\title{
A study on the relationship between attachment styles, self esteem and loneliness amongst adolescents
}

\author{
Divya Thakkar ${ }^{1}$, Neha Haria ${ }^{2}$, Veena Kumar \\ ${ }^{1,2}$ Undergraduate student, Department of Psychology, KC College, Mumbai. \\ ${ }^{3} \mathrm{Head}$, Department of Psychology, KC College, Mumbai. \\ E-mail - veena_sunshine@yahoo.co.in
}

\begin{abstract}
Background: Attachment styles, self esteem and social relationships are inextricably linked. It is well known that adolescence is a period where self esteem depends on a number of factors like family, upbringing, loneliness and peers. The following study was carried to assess the relationship between self esteem, attachment styles and loneliness in college students.

Methods: 40 girls and 40 boys aged 18-21 years studying in colleges across Mumbai were subjects for the study. The subjects were administered the Rosenberg self esteem scale, the UCLA loneliness scale and the Adult attachment scale. The scores on all scales were compared for boys and girls and Pearson's correlation was carried across all scales.

Results: No differences between boys and girls were observed in any of the scales administered. A negative correlation between self esteem and loneliness was observed. Similar negative correlations were observed between self esteem and anxiety as well as avoidant attachment styles. A positive correlation was observed between loneliness and anxiety as well as avoidant attachment styles.

Conclusion: Self esteem is linked to attachment styles and loneliness in college going students. Further studies in larger samples are warranted.
\end{abstract}

Key words: adolescents, self esteem, attachment, attachment styles, loneliness.

(Received $-27^{\text {th }}$ March 2016, Peer Review done $-25^{\text {th }}$ May 2016, Accepted $-2^{\text {nd }}$ June 2016)

\section{INTRODUCTION}

Attachment is the positive emotional bond that develops between a child and a particular individual. The degree of security experienced in interpersonal relationships [1]. Differential style initially develops in the interactions between infant and caregiver when the infant acquires the basic attitudes about self-worth and interpersonal trust [2]. Different attachment styles are as follows: [3]

- Secure attachment style- A style characterized by high self-esteem and high interpersonal trust. This is the most successful and most desirable attachment style.

- Fearful-avoidant attachment style- A style characterized by low self-esteem and lowinterpersonal trust. This is the most insecure and least adapted attachment style.

- Preoccupied attachment style- A style characterized by low self-esteem and high interpersonal trust. This is the conflicted and somewhat insecure style in which the individual strongly desires a close relationship but feels that she or he is unworthy of the partner and is thus vulnerable to being rejected. 
- Dismissing attachment style- A style characterized by high self-esteem and low interpersonal trust. This is a conflicted and somewhat insecure style in which the individual feels that she or he deserves a close relationship but is frustrated because of mistrust of potential partners. The result is the tendency to reject the other person at some point in the relationship to avoid being the one who is rejected.

Knowing who you are and liking who you are two different things. Although adolescents become increasingly accurate in understanding who they are (their self-concept), this knowledge does not guarantee that they like themselves (their self-esteem) any better. Self-esteem is defined as the judgment a person makes about his or her self worth [4].

During early adolescence, girl's self-esteem tends to be lower and more vulnerable than boys' [5-7]. One reason is that, compared to boys, girls tend to be more concerned about physical appearance and social success- in addition to academic achievement. Although boys are also concerned about these thing, their attitudes are often more casual.

Race and ethnicity also play a role in self-esteem, but their impact has lessened as prejudicial treatment of minorities has eased. Early studies argued that minority status would lead to lower self-esteem, and this was initially supported by research. For instance, some developmental psychologists have considered race and gender simultaneously, coining the term ethgender to refer to the joint influence of race and gender [8]. Societal pressures are also high during adolescence. At the same time, their dependence on adults declines. This increasing dependence on the peer group enables adolescents to forge close relationships. Comparing themselves to others helps them clarify their own identities [9].

Loneliness is the unpleasant emotional and cognitive state based on desiring close relationships but being unable to attain them. The origins of loneliness appear to include a combination of genetic factors, attachment style and a lack of opportunity for early social experiences with peers. Differences in loneliness could be the result of rejection based on differences in interpersonal behavior [10]

According to Bowlby, children, overtime, internalize experiences with caretakers in such a way that early attachment relations come to form a prototype for later relationships outside the family. Bowlby [11] identifies two key features of these internal representations or working models of attachment viz. (a) whether or not the attachment figure is judged to be the sort of person who in general responds to calls for support and protection; [and] (b) whether or not the self is judged to be the sort of person towards whom anyone, and the attachment figure in particular, is likely to respond in a helpful way.

Research has examined the nature of internal working models in relation to children's early attachment styles. The data show, for example, that children classified as ambivalent hold negative view of themselves, but the data are not as consistent with respect to children classified as avoidant [12-13]. A considerable body of research also links the child's attachment style at 12 or 18 months to the child's social and emotional adjustment through early childhood [14].

Main has developed an Adult Attachment Interview [15] that explores adults' representations of childhood attachment relations. On the basis of these interviews, mothers have been classified into attachment groups that parallel the three childhood attachment patterns (secure, anxious-resistant and avoidant) and are predictive of the quality of the mother's interaction with her own child and the security of the child's attachment [16-17].

Researchers conducted an analysis for self-esteem, the effects of life satisfaction, sex and age. Analysis yielded significantly higher self-esteem for men than women amongst older subjects and those with high life satisfaction due to adolescent, aging, female, gender identity, personal satisfaction, self concept [18]. Conversely, participation in senior center activities protects against loneliness in older adults living alone [19]. Contact with friends is more important than contact with adult children and other family members in preventing loneliness [20] and the chronic unavailability of social partners with whom to enjoy social activities have been associated with greater loneliness [21].

Personality characteristics related to loneliness include traits from the "Big Five" such as greater neuroticism, less conscientiousness and less agreeableness, as well as lower self-esteem and greater shyness, hostility, insecure attachment styles, anxiety, pessimism and fear of negative evaluation [22-23]. Chronic loneliness is the result of an interaction between a genetic bias and life circumstances that are in 
part beyond our control. Even when they succeed in eliciting nurturing support from a friend or loved one, they tend to perceive the exchange as less fulfilling [24].

Parental attachment was negatively related to emotional problems among adolescent students in several studies [25]. An Indian study shows that male and female significantly differ in perception of parental attachment, family environment, mothers' warmth and fathers' warmth. It was also found that no significant difference between male and female adolescents on emotional problems. According to the research females perceive better attachment, better family environment and better warmth from both mother and father when compared to males. However, both males and females have similar level of emotional problems [26].

Crocker [27] empirically stated that self-esteem is powerfully related to the affective tone of daily experiences including positive effect, life satisfaction, anxiety, hopelessness and depression. Indian research too states that there will be a positive strong correlation between life satisfaction and self-esteem [28].

On setting aside the greater number of objective stressors in their lives, the lonely express proportionately greater feelings of helplessness and threat than those who are not lonely. The lonely, both young and old, perceived the hassles and stresses of everyday life to be more severe than did their non-lonely counterparts. Compounding the problem, the lonely found the small, social uplifts of everyday life to be less intense and less gratifying [29]. The aim of the current study was to assess the relationship between attachment styles, self-esteem and loneliness among adolescents.

\section{METHODOLOGY}

\section{Hypotheses}

- There would be a negative correlation between self-esteem scores and loneliness scores.

- There would be a negative correlation between self-esteem scores and avoidance (attachment style) scores.

- There would be a negative correlation between self-esteem scores and anxiety (attachment style) scores.

- There would be a positive correlation between loneliness scores and avoidance (attachment style) scores.

- There would be a positive correlation between loneliness scores and anxiety (attachment style) scores.

Questionnaires were distributed randomly amongst 40 girls and boys respectively.

The materials used in the study were -

- Rosenberg's Self-Esteem Scale (1964) [30] - This scale was used by the researches to test selfesteem. It is a 10-item scale that measures global self-worth by measuring both positive and negative feelings about the self. The scale is believed to be unidimensional. All items are answered using a 4 point Likert Scale format ranging from strongly agree to strongly disagree. There was no time limit to answer the questions. Items 2, 5, 6, 8, 9 are reversed scored. Strongly disagree was given- 1 point, disagree- 2 points, agree- 3 points and strongly agree- 4 points. Scores were kept on a continuous scale. Higher scores indicated higher self-esteem.

- University of California, Los Angeles (UCLA) Loneliness Scale [31] - This scale measured loneliness. A 20-item scale was designed to measure one's subjective feelings of loneliness as well as feelings of social isolation. Participants were asked to rate each item as either O ("I often feel this way"), S ("I sometimes feel this way"), R ("I rarely feel this way"), N ("I never feel this way"). The measure has been revised two times since its first publication: once to create reverse score items and once to simplify the wording. There was no time limit to answer the questions.

- Adult Attachment Scale [32] - This scale contains three subscales, each composed of six items measuring anxiety close and depend. Participants were asked to rate each item on a 5 point rating scale ranging from ' Not at all characteristic of me' to 'Very characteristic of me'.

Repeated measures design was used wherein same variable or factors were exposed to all participants. 
Three questionnaires testing self-esteem, loneliness and attachment styles were distributed together to participants who were randomly selected across colleges in Mumbai. Participants were assured of confidentiality of the responses. Doubts were clarified by the researchers. There was no time limit to answer the questionnaires. After all questionnaires were collected from the respondents, they were manually scored and further statistical analysis was done using Microsoft Excel. Results and discussions were done with reference to theories and past research.

\section{STATISTICAL ANALYSIS}

The entire statistical analysis was done using computerized Graph Pad software. The difference on scores on various scales between boys and girls was assessed using the independent samples $t$ test while correlation between all variables was done using Pearson's correlation. The data was analyzed and tabulated

\section{RESULTS}

A total of 40 boys and 40 girls were chosen for the study randomly across colleges in Mumbai. No clear randomization was followed but the sample was chosen from 5 colleges all over Mumbai.

Table 1 shows the scores on various scales between boys and girls and the differences between them. No differences between boys and girls were observed in any of the scales administered.

Table 2 shows the correlation pattern between scores on the various scales. A negative correlation between self esteem and loneliness was observed. Similar negative correlations were observed between self esteem and anxiety as well as avoidant attachment styles. A positive correlation was observed between loneliness and anxiety as well as avoidant attachment styles.

Table 1 - Analysis of scores between boys and girls on all the scales

\begin{tabular}{|ccccc|}
\hline Scale & $\begin{array}{c}\text { Boys } \\
(\mathrm{n}=40) \\
\text { Mean } \pm \mathrm{SD}\end{array}$ & $\begin{array}{c}\text { Girls } \\
(\mathrm{n}=40) \\
\text { Mean } \pm \text { SD }\end{array}$ & t value & $\mathrm{p}$ value \\
\hline $\begin{array}{c}\text { Rosenberg Self } \\
\text { Esteem Scale }\end{array}$ & $28.56 \pm 3.81$ & $28.47 \pm 3.79$ & 0.1059 & $0.9159 \mathrm{NS}$ \\
\hline $\begin{array}{c}\text { UCLA Loneliness } \\
\text { Scale }\end{array}$ & $19.02 \pm 11.2$ & $17.93 \pm 10.03$ & 0.4609 & $0.6462 \mathrm{NS}$ \\
\hline $\begin{array}{c}\text { Anxiety } \\
\text { Attachment Style }\end{array}$ & $15.92 \pm 5.45$ & $17.97 \pm 5.56$ & 1.6719 & $0.0986 \mathrm{NS}$ \\
\hline $\begin{array}{c}\text { Avoidant } \\
\text { Attachment Style }\end{array}$ & $32.47 \pm 8.92$ & $35.5 \pm 6.9$ & 1.7245 & $0.0866 \mathrm{NS}$ \\
\hline
\end{tabular}

NS - not significant (Statistics done using unpaired t test)

Table 2 - Correlation between various scales

\begin{tabular}{|ccc|}
\hline $\begin{array}{c}\text { Scales } \\
(\mathrm{n}=80, \mathrm{df}=79)\end{array}$ & $\mathrm{r}$ & $\mathrm{p}$ value \\
\hline Self esteem and Loneliness scales & -0.4785 & $<0.001^{*}$ \\
\hline Loneliness and Anxiety attachment & 0.4175 & $<0.001^{*}$ \\
\hline Loneliness and Avoidance attachment & 0.4991 & $<0.001^{*}$ \\
\hline Self esteem and Anxiety attachment & -0.3596 & $<0.01^{*}$ \\
\hline Self esteem and Avoidance attachment & -0.3226 & $<0.01^{*}$ \\
\hline
\end{tabular}

*significant $(p<0.05)$ (Pearson's correlation used) 


\section{DISCUSSION}

People having high self-esteem, tend to have higher levels of confidence and hence they seem to be more out-going which makes them less lonely as compared to the people who have low self-esteem, low levels of confidence and who seem to be less outgoing [33].

If people have high self-esteem, they are likely to indulge in more activities. Their time and energy is diverted in the activities, which leaves less time for them to be lonely. According to transactional model, low self-esteem and loneliness reciprocally affect one another across time. Research in childhood [34], adolescence [35], and adulthood [36] has shown a consistent relationship with loneliness. Particularly in adolescence, one's perception of one's social relationships is of crucial importance to one's self-esteem [37]. Indeed, adolescents tend to define themselves in terms of social relationships and are increasingly aware of and concerned about their social status [38].

People with avoidant attachment style tend to feel that they are unwanted and they do not matter to anyone, due to which they tend to have low self-esteem. People with avoidant attachment style usually have pessimistic views about life, self which in turn affects their personality, academics, self-esteem, etc. [39]. Children develop the ability to self-soothe in infancy, and they continue to draw upon this skill throughout their lives; when troubled, they engage in instrumental coping and a deactivating strategy that minimizes the importance of emotions and close relationships [40]. They carry these tendencies into their relationships as well, cultivating a pervasive fear of closeness and emotional intimacy, and struggling with issues regarding acceptance of and trust in close others. They learned in childhood that other people can't be depended upon in times of trouble; as a result, they have difficulty seeking and accepting support from others and are likely to withdraw during difficult or stressful periods within their relationships [41].

Children with anxiety attachment style are usually less socializing than their counterparts which leads to low self-esteem in them. Trusting people wouldn't be that easy for them, hence affecting their interpersonal relationship and self esteem [42]. Adolescents with anxious attachment often doubt themselves and struggle with feeling misunderstood, underappreciated, and worthless. They have low levels of independence and self-sufficiency. They tend to have pessimistic views of others' intentions and potential to give reliable care [43].

People with avoidant attachment style generally tend to be rebellious and short-tempered in nature and non-adjusted in society, resulting in loneliness. Since they are avoided and lonely, they may seek sympathy and attention [44]. A study showed that pessimistic and avoidant emotional strategies of individuals are related to their loneliness for more than one year [44]. On the other hand, lack of secure attachment can lead to difficulties in regulating emotions and relating to others, engendering a vulnerability to psychological distress, loneliness and depression [45].

People with anxious attachment style tend to get frustrated easily and do not trust people readily. Hence people won't be willing to keep relations with them which make them feel lonely. The prevalence of loneliness varies according to attachment style, with the insecure styles more likely to experience loneliness [46].

The study is marred by a small sample size and probably larger sample sizes with regression analyses as statistics could have been used. Overall further studies in this area in college students are warranted to understand this facet better.

\section{REFERENCES}

1. Bartholomew K, Horowitz LM. Attachment styles among young adults: a test of a four-category model. J Personal Soc Psychol 1991;61(2):226-44.

2. Shaver PR, Brennan KA. Attachment styles and the" Big Five" personality traits: Their connections with each other and with romantic relationship outcomes. Personal Soc Psychol Bull 1992;18(5):536-45.

3. Simpson JA. Influence of attachment styles on romantic relationships. J Personal Soc Psychol 1990;59(5):971-80.

4. Greenwald AG, Banaji MR. Implicit social cognition: attitudes, self-esteem, and stereotypes. Psychol Rev 1995;102(1):4-27. 
5. Heaven P, Ciarrochi J. Parental styles, gender and the development of hope and self-esteem. Eur J Personality 2008;22(8):707-24.

6. McLean KC, Breen AV. Processes and content of narrative identity development in adolescence: gender and well-being. Dev Psychol 2009;45(3):702-10.

7. Mäkinen M, Puukko-Viertomies LR, Lindberg N, Siimes MA, Aalberg V. Body dissatisfaction and body mass in girls and boys transitioning from early to mid-adolescence: additional role of self-esteem and eating habits. BMC Psychiatry 2012;12(1):1.

8. Owens TJ, Stryker S, Goodman N. Extending self-esteem theory and research: Sociological and psychological currents. Cambridge University Press; 2006.

9. Abouserie R. Sources and levels of stress in relation to locus of control and self esteem in university students. Educ Psychol 1994;14(3):323-30.

10. Peplau LA. Loneliness: A sourcebook of current theory, research, and therapy. John Wiley \& Sons Inc; 1982.

11. Bowlby J. Attachment and loss, vol. II: Separation. Basic Books; 1973.

12. Cassidy J, Asher SR. Loneliness and peer relations in young children. Child Dev 1992;1:350-65.

13. Main M, Kaplan N, Cassidy J. Security in infancy, childhood, and adulthood: A move to the level of representation. Monogr Soc Res Child Dev 1985;1:66-104.

14. Hesse E, Main M. Disorganized infant, child, and adult attachment: Collapse in behavioral and attentional strategies. J Am Psychoanal Assoc 2000;48(4):1097-127.

15. Kobak RR, Sceery A. Attachment in late adolescence: Working models, affect regulation, and representations of self and others. Child Dev 1988;2:135-46.

16. Crowell JA, Treboux D. A review of adult attachment measures: Implications for theory and research. Soc Developm 1995;4(3):294-327.

17. Grossmann K, Fremmer-Bombik E, Rudolph J, Grossmann KE. Maternal attachment representations as related to child-mother attachment patterns and maternal sensitivity and acceptance of her infant. Relations within families. 1988:241-60 (Oxford University Press).

18. Van Gaalen RI, Dykstra PA. Solidarity and conflict between adult children and parents: A latent class analysis. J Marr Family 2006;68(4):947-60.

19. Strong DD, Bean RA, Feinauer LL. Trauma, attachment, and family therapy with grandfamilies: A model for treatment. Child Youth Serv Rev 2010;32(1):44-50.

20. Pinquart M, Feußner C, Ahnert L. Meta-analytic evidence for stability in attachments from infancy to early adulthood. Attach Hum Dev 2013;15(2):189-218.

21. Rook KS. Research on social support, loneliness, and social isolation: Towards an integration. Rev Personal Soc Psychol 1984;5:239-64.

22. DiTommaso E, Brannen C, Burgess M. The universality of relationship characteristics: A cross-cultural comparison of different types of attachment and loneliness in Canadian and visiting Chinese students. Soc Behav Personality 2005;33(1):57-68.

23. Cacioppo JT, Hughes ME, Waite LJ, Hawkley LC, Thisted RA. Loneliness as a specific risk factor for depressive symptoms: cross-sectional and longitudinal analyses. Psychol Aging 2006;21(1):140-51.

24. Cacioppo JT, Hawkley LC, Crawford LE, Ernst JM, Burleson MH, Kowalewski RB, Malarkey WB, Van Cauter E, Berntson GG. Loneliness and health: Potential mechanisms. Psychosom Med 2002;64(3):407-17.

25. Hawkley LC, Cacioppo JT. Loneliness matters: A theoretical and empirical review of consequences and mechanisms. Ann Behav Med 2010;40(2):218-27.

26. Bharathi AV, Sasikala S, Nandhitha E, Karunanidhi S. Optimism, Self-esteem and Social Support among Students with High and Low Test Anxiety. J Psychosoc Res 2015;10(1):33-8.

27. Crocker J, Park LE. The costly pursuit of self-esteem. Psychol Bull 2004;130(3):392-414.

28. Vithya V, Karunanidhi S, Sasikala S. Influence of Optimism, Parental Expectations and Peer Attachment on Subjective Happiness of Female College Students. J Indian Acad Appl Psychol 2015;41(1):95-9.

29. Cacioppo JT, Hawkley LC. Social isolation and health, with an emphasis on underlying mechanisms. Persp Biol Med 2003;46(3):S39-52.

30. Robins RW, Hendin HM, Trzesniewski KH. Measuring global self-esteem: Construct validation of a singleitem measure and the Rosenberg Self-Esteem Scale. Personal Soc Psychol Bull 2001;27(2):151-61.

31. Russell DW. UCLA Loneliness Scale (Version 3): Reliability, validity, and factor structure. J Personal Assess 1996;66(1):20-40.

32. Fraley RC, Waller NG, Brennan KA. An item response theory analysis of self-report measures of adult attachment. J Personal Soc Psychol 2000;78(2):350-65.

33. Kling KC, Hyde JS, Showers CJ, Buswell BN. Gender differences in self-esteem: a meta-analysis. Psychol Bull 19991;125(4):470-500. 
34. Fordham K, Stevenson-Hinde J. Shyness, friendship quality, and adjustment during middle childhood. J Child Psychol Psychiatry 1999;40(5):757-68.

35. Allen JP, Hauser ST, Bell KL, O'Connor TG. Longitudinal assessment of autonomy and relatedness in adolescent-family interactions as predictors of adolescent ego development and self-esteem. Child Dev 1994; 1:179-94.

36. McAuley E, Mihalko SL, Bane SM. Exercise and self-esteem in middle-aged adults: Multidimensional relationships and physical fitness and self-efficacy influences. J Behav Med 1997;20(1):67-83.

37. Perlman D, Peplau LA. Toward a social psychology of loneliness. Personal Relat 1981;3:31-56.

38. Parkhurst JT, Asher SR. Peer rejection in middle school: Subgroup differences in behavior, loneliness, and interpersonal concerns. Dev Psychol 1992;28(2):231-42.

39. Cusimano MD, Sameem M. The effectiveness of middle and high school-based suicide prevention programmes for adolescents: a systematic review. Injury Prev 2011;17(1):43-9.

40. Doohan EA, Carrère S, Riggs ML. Using relational stories to predict the trajectory toward marital dissolution: The oral history interview and spousal feelings of flooding, loneliness, and depression. J Fam Commun 2010;10(1):57-77.

41. Creemers DH, Scholte RH, Engels RC, Prinstein MJ, Wiers RW. Implicit and explicit self-esteem as concurrent predictors of suicidal ideation, depressive symptoms, and loneliness. J Behav Ther Exp Psychiatry 2012;43(1):638-46.

42. Bögels SM, Brechman-Toussaint ML. Family issues in child anxiety: Attachment, family functioning, parental rearing and beliefs. Clin Psychol Rev 2006;26(7):834-56.

43. Hazan C, Shaver P. Romantic love conceptualized as an attachment process. J Personal Soc Psychol 1987;52(3):511-33.

44. Männikkö K. Adult attachment styles: A Person-oriented approach. University of Jyväskylä; 2001.

45. DiTommaso E, Brannen-McNulty C, Ross L, Burgess M. Attachment styles, social skills and loneliness in young adults. Personal Individ Diff 2003;35(2):303-12.

46. Ireland JL, Power CL. Attachment, emotional loneliness, and bullying behaviour: A study of adult and young offenders. Aggr Behav 2004;30(4):298-312.

\author{
Acknowledgements - Nil \\ Source of Funding - Nil \\ Conflict of Interest $-\mathrm{Nil}$
}

